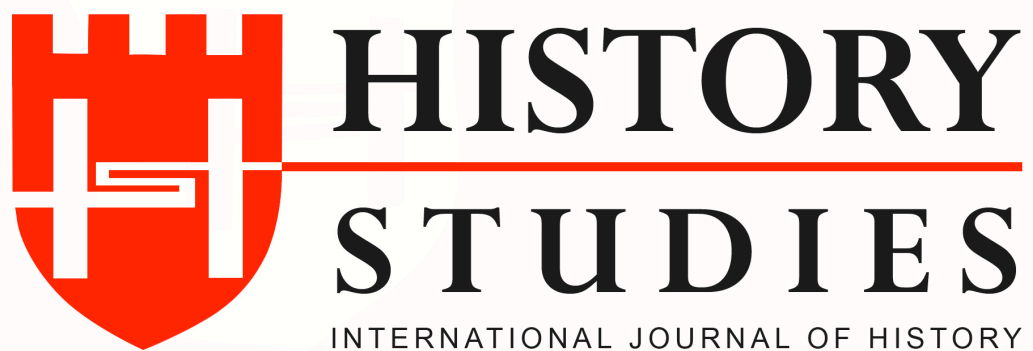

ISSN: 13094173 (Online) 1309 - 4688 (Print)

Volume 12 Issue 1, February 2020

DOI Number: 10.9737/hist.2020.832

Araştırma Makalesi

Makalenin Geliş Tarihi: 29.09.2019 Kabul Tarihi: 06.01.2020

Atıf Künyesi: Murat Tural, “Cermenlerin Dini Dönüşümü”, History Studies, 12/1, Şubat 2020, s. 317-

329.

\title{
Cermenlerin Dini Dönüşümü
}

\section{The Religious Transformation of the Germanic Peoples}

\author{
Dr. Murat Tural \\ ORCID No:0000-0002-1361-4656 \\ Ondokuz Mayıs Üniversitesi
}

$\ddot{\mathbf{O z}}$

Roma İmparatorluğu'nun içine tam anlamıyla nüfuz etmeden önce putperestlik veya Aryanizm'den birini kabul eden çeșitli Cermen kavimleri ilerleyen süreçte her ikisinden de vazgeçerek Katolik kültüre ister istemez uyum sağlamışlardı ancak uzun zamana yayılan bu dönüşümün başlangıcında koskoca bir imparatorluğun Avrupa'daki toprakları ortadan kalkmıştı. Cermenlerin önemli bir kısmı Hristiyan olmasına karșın, bu süreç kanlı başladı. Her șeye rağmen bu hâl kimilerinin kabul ettiği gibi Orta Çağ'ın bütününde yaşanmadı. Siyasi yetkeyi ellerine geçiren çeşitli kavimler bir zaman sonra iktidarlarını devam ettirebilmek için bulundukları topraklarda istikrarı hâkim kılmak istemişlerdi. Cermen kavimlerinin hemen tamamı ne Doğu ne de Batı Kilisesi'nin tasvip ettiği bir mezhebi tecrübe etmişlerdi. Bu, adını Arius adlı bir papazdan alan Aryanizm idi. Arius ile direkt temas kurulmamışsa da Ulfila adlı bir misyoner sayesinde Avrupa'nın yeni sakinlerinin inancı bu mezhep doğrultusunda şekillenmişti. Ne var ki bu kavimlerin hareketli devirlerinin üzerinden birkaç yüzyıl geçtikten sonra ne krallıklarından ne de kendilerini farklı kılan Aryanizm'den eser kalmıştı.

Anahtar Kelimeler: Orta Çağ, Cermenler, Din, Kilise, Aryanizm.

\begin{abstract}
The various Germanic tribes which adopted paganism or Arianism before being fully penetrated into the Roman Empire abandoned both religious beliefs and unavoidably adapted to the Catholic culture in the forthcoming process. However, at the onset of this transformation which extended over a long period of time, a gigantic empire's control over its territories in Europe had already been lost. Even though a large part of Germanic peoples had already been converted to Christianity, this transformation process began with bloody wars. Nevertheless, contrary to assertions by certain scholars, this was not necessarily the case throughout the entire Middle Age. The various tribes which obtained the political power later aspired to ensure that the political stability dominated over their territories so as to continue to maintain their powers. Almost all German tribes practiced a religious sect which was approved by neither the Eastern Church nor the Western Church. This sect was Arianism which was named after a priest called Arius. Even if there was no direct contact with Arius himself, the religious belief of new inhabitants of Europe was shaped by this sect by virtue of a missionary called Ulfilas. However, following the passage of a few centuries after the dynamic period of these Germanic tribes, there remained trace of neither their kingdoms nor Arianism which attributed a unique character to them.
\end{abstract}

Keywords: Middle Ages, Germanic peoples, Religion, Church, Arianism. 


\section{Giriş}

Roma İmparatorluğu'nun önce ikiye ayrılmasının, akabinde Avrupa'daki kısmının ortadan kalkmasının Hunlarla beraber başlıca sorumlusu olan Cermen kavimleri birbirlerinden hem biyolojik hem de kültürel olarak çok da farklı değillerdi. M.S. VI. yüzyılın ortasında eserini kaleme alan Got kökenli tarihçi Jordanes' in "arı kovanından fırlamışçasına" diyerek bahsettiği bu kesif insan kalabalığının kökeni tartışmalar olmakla birlikte muhtemelen İskandinavya'ya dayanıyordu. Roma'nın yüzyıllardır işlerlik kazandırdığı düşünceye göre, Roma İmparatorluğu medeni bir dünya idi ve Roma'nın güvenliği medeniyetin güvenliği demekti. ${ }^{2}$ Hâl böyle olunca Roma'nın çöküşü genel itibarıyla imparatorluğun yıkılış hikâyesi ve medeniyetin sonu gibi ezberler ile anlamlandırılmaya çalışıldı. Oysa çoğu Avrupa tarihçisinin belirttiği üzere, sonraki asırlarda Avrupa tarihinde büyük etkiler yaratmış olan 1348'deki Büyük Veba, 30 Yıl Savaşları ve II. Dünya Savaşı'nın medeniyetin sonunu getirdiğine dair değerlendirmelere rastlanmadı. Fakat modern zamana yaklaştıkça yıkım eksenli bu düşünce kısmen değişime uğradı. Örneğin bu meseleler üzerine epey çalışmaları olan Pohl'a göre, eğer bir yıkım var idi ise, bu imparatorluğun Avrupa kısmında cereyan etmiş bir yıkımdı. ${ }^{3}$ Roma İmparatorluğu'nun çöküşü bütün eski imparatorluk topraklarında aynı etkiye sahip olmamıştı. Akdeniz kıyısında ve özellikle mezkûr denizin doğusunda fazla bir değişim görülmedi. Bu yüzden bazı araştırmacılarca illaki bir karanlık çağ yakıştırması yapılacaksa, bunun kapsam alanının Kuzeybatı Avrupa için daha uygun düştüğü ifade edilmektedir. ${ }^{4}$

Çeşitli kavimler imparatorluğun batı kısmının varlığına son verseler de, doğu yani Konstantinopolis barbar istilaları kavramıyla batıdan iki yüz yıl önce tanışmıştı. ${ }^{5}$ Zira İmparator Valens'in 376'da Gotlara Danube'yi aşıp imparatorluk sınırına girmeleri için izin vermesinden, 476'ya yani Odoacer'ın son Roma imparatoru Romulus'u tahtından etmesine değin tam yüz sene geçmişti. ${ }^{6}$ Fakat ilk tarih, imparatorluk içinde yaşanacak olan uzun soluklu gelişmelerin ilk halkasını oluşturdu. ${ }^{7}$ İmparatorluğun çöküşü günlerinde papa, tıpkı kilise gibi imparatorluğun da bölünemez olduğunu düşünüyordu. Oysa doğuda imparator Zeno (ö. 491), batıda kendisine eş bir imparator görmeye çok da istekli değildi. ${ }^{8}$ Dolayısıyla Cermen kavimlerinin Avrupa'nın çeşitli yerlerinde mukim olmalarından sonra yeni bir mücadele devresi başlamış oldu. Cermenler başlangıçta hayal etmedikleri bir başarı sonucundaki kazanımlarını kaybetmemek için, doğulu imparatorlar ise tek imparatorluk fikrinin iteklemesiyle kıtada savaş hâlinin sürmesine katkı sağlamışlardı. Fakat şiddet sadece batıda

${ }^{1}$ Jordanes, The Origin and Deeds of the Goths, trans. Charles C. Mierow, Princeton University Press, Princeton 1908, s. 7.

${ }^{2}$ F. Haverfield, The Romanization of Roman Britain, At the Clarendon Press, Oxford 1912, s. 10.

3 Walter Pohl, "Christian and Barbarian Identities in the Early Medieval West: Introduction", Post-Roman Transitions Christian and Barbarian Identities in the Early Medieval West, ed. Walter Pohl-Gerda Heydemann, Brepols, Turnhout 2013, s. 1-2. James'e göre de, barbar istilalarının şehirlerdeki yapıların tümünün yıkılmasının sorumlusu olarak gösterilmesi büyük yanlışlardan biridir. Edward James, The Origin of France from Clovis to Capetians 500-1000, The Macmillan Press, London 1982, s. 46.

${ }^{4}$ Janet L. Abu-Lughod, Before European Hegemony The World System A.D. 1250-1350, Oxford University Press, New York 1989, s. 43.

${ }^{5}$ Walter Goffart, "The Theme of 'The Barbarian Invasions' in Late Antique and Modern Historiography", Das Reich und die Barbaren, Evangelos K. Chrysos-Andreas Schwarcz, Böhlau Verlag, Köln 1989, s. 92.

${ }^{6}$ Guy Halsall, Barbarian Migrations and the Roman West 376-568, Cambridge University Press, Cambridge 2007, s. 21.

7 Peter Heather, "Goths and Huns, c. 320-425", The Cambridge Ancient History, Vol. XIII, ed. Averil CameronPeter Garnsey, Cambridge University Press, Cambridge 2007, s. 521-522; Halsall, Barbarian Migrations and the Roman West 376-568, s. 503.

${ }^{8}$ J. M. Wallace-Hadrill, The Barbarian West A.D. 400-1000, Harper Torchbooks, New York 1962, s. 32; Simon Baker, Eski Roma Bir İmparatorluğun Yükselişi ve Çöküşü, çev. Ekin Duru, Say Yayınları, İstanbul 2017, s. 415416.

\section{History Studies}


barbarlar elinden gerçekleşmiyordu. Miladi 400 yılında Konstantinopolis'te yaşayan 7000 Got kiliseye dolduruldu ve yakılarak öldürüldü. ${ }^{9}$ Mütedeyyin Hristiyanlar da bu olay üzerine şehrin ortasında pis bir mezar görüntüsünden rahatsızlıklarını izhar etmişlerdi. ${ }^{10}$

Barbar kavimlerden bahseden Grek ve Romalı yazarlar eserlerinde bu kavimlerle ilgili etnik özelliklerden ziyade o dönemin önemli olaylarını yansıtmayı tercih etmişlerdir. Kısır bir özellik arz eden etnik tariflerde ise Heredot gibi eski Grek yazarlarının çizdiği kalıbın dışına çok fazla çıkamamışlardır. ${ }^{11}$ M.Ö. V. yüzyılda Herodot, uzaklarda Akdeniz'in ötesinde vahşi ulusların bulunduğunu söylemiş, Roma da bu söylemi olduğu gibi kabul etmiştir. ${ }^{12}$ Tarih boyunca Avrupa düşüncesinin ana temalarından biri olan "Biz" ve "onlar" şeklinde bir kategorilendirme ${ }^{13}$ en çok göç çağı ve sonrasında kuvvet kazanmıştır. Bu manada IV. yüzyılda barbarların en korkuncu olarak görülen ${ }^{14}$ ve sonraki gelişmeler için bir manivela işlevi icra eden Hunlar uzaktan İskitya'nın doğu sınırından çıkıp gelmişlerdir. ${ }^{15}$ Meşhur Konstantin'in de hayatını kaleme alan Eusebius'a (ö. 339) göre Roma İmparatorluğu, Hristiyanlığın yayılmasını kolaylaştırmak için İsa'nın gelişinden evvel Tanrı'nın tasarrufunun bir sonucuydu. ${ }^{16}$ Yani onun putperest bir geçmişe sahip olması bir hazırlık devresi demekti. Konstantin'in dini tercihinden önce Hristiyanlık Batı Avrupa'da çok küçük bir cemaate sahipti. Hristiyanlığı imparatorluğun resmi dini hâline getirmek yoluyla Konstantin'in dini politikasının tamamlayıcısı I. Theodosius (ö. 395) oldu. ${ }^{17}$ Bundan sonra yaşanacak olan gelişmeleri öngören ve bu yüzden putperest Roma dönemi için Tanrısal bir plan çizen Eusebius'tan iki yüzyıl sonra yazan Sevilyalı Isidore'e (ö. 636) göre ise Hunlar, doğru yoldan sapmış kulları ikaz için Tanrı'nın bir cezalandırması niteliğindeydi. ${ }^{18}$ Biri Doğu'dan biri Batı'dan olan iki yazarın da isabet tutturduğunu kabul edersek, yeni inanca dahil olan imparatorluk sakinleri birkaç asır içinde çok büyük günahlara gark olmuşlardı!

Volume 12

\section{Atalar Dini ve Aryanizm}

Cermenlerin detaylarına çok fazla vakıf olamadığımız putperestlik temelli inançları hakkındaki ilk bilgiler, onların III. ve IV. yüzyıllardaki hareketli devirlerini görme şansı olmayan birkaç yazarın tespitlerine dayanır. ${ }^{19}$ M.Ö. I. yüzyılın ortasında yazan Gaius Julius Caesar, onların dinsel törenleri yöneten Druid yani bir ruhbanlar sınıfının olmadığını, fakat

\footnotetext{
9 Socrates, "Ecclesiastical History", Nicene and Post-Nicene Fathers of the Christian Church, Vol. II, ed. Philip Schaff-Henry Wace, The Christian Literature Company, New York 1890, s. 309, 368.

${ }^{10}$ Zosimus, New History, trans. Ronald T. Ridley, Australian Association for Byzantine Studies, Melbourne 1982, s. 108-109.

${ }^{11}$ Patrick J. Geary, Before France and Germany: The Creation and Transformation of the Merovingian World, Oxford University Press, New York 1988, s. 39. Ayrica bkz. Paul Cartledge, The Greeks A Portrait of Self and Others, Oxford University Press, New York 2002, s. 51-77.

${ }^{12}$ Halsall, Barbarian Migrations and the Roman West 376-568, s. 46; Andrew Gillett, "The Mirror of Jordanes: Concepts of the Barbarian, Then and Now", A Companion to Late Antiquity, ed. Philip Rousseau, Blackwell, London 2009, s. 399-400.

${ }^{13}$ D. A. Tirr, "The Attitude of the West towards the Avars", Acta Archaeologica, 28, 1.2, 1976, s. 111.

${ }^{14}$ Wallace-Hadrill, The Barbarian West A.D. 400-1000, s. 9.

${ }^{15}$ Claudian, Against Rufinus, trans. Maurice Platnauer, Harward University Press, London 1990, s. 49; Baker, Eski Roma, s. 374-375.

${ }^{16}$ Eusebius, "Oration in Praise of Constantine", Nicene and Post Nicene Fathers, Vol. I, ed. P. Shaff-H. Wace, Charles Scribner's Sons, New York 1904, s. 606. Aksine imparatorluğun yıkılış nedenini Hristiyanlaşması olarak gören tarihçiler de vardır. Peter Jones, Geldim Gördüm Yendim, çev. Funda Sezer, Say Yayınları, İstanbul 2019, s. 356.

${ }^{17}$ Alexander A. Vasiliev, Bizans İmparatorluğu Tarihi, çev. Tevabil Alkaç, Alfa Yayınları, İstanbul 2016, s. 98 vd.

${ }^{18}$ Isidore of Seville, History of the Goths, Vandals, and Suevi, trans. G. Donini-G. B. Ford, Brill, Leiden 1970, s. 15.

${ }^{19}$ Montesquieu, Kanunların Ruhu Üzerine, çev. Berna Günen, Türkiye İş Bankası Kültür Yayınları, İstanbul 2019, s. 760.
} 
özellikle menfaatlerini gördükleri tanrılarının bulunduğunu söylemiştir. Bu tanrılardan isimlerini saydığı Sol, Vulcanus ve Luna'dan ilki İskandinav mitolojisindeki Güneş'e; ikincisi ve üçüncüsü ise sırasıyla Romalı yazarın pek yabancısı olmadığı Yunan mitolojisindeki Ateş ve Ay'a karşıılık gelmektedir. Caesar, onların bazı hususlardaki muhafazakâr tutumlarına temas etme gereği de duymuştur. Örneğin nehirlerde büyük oranda çıplak bir vaziyette kadın-erkek ortak yıkanma alışkanlıkları olmalarına rağmen, yirmi yaşından önce ilişkiyi utanç verici olarak kabul ettiklerini, hatta iffetlerini en uzun süre koruyanların oldukça muteber kişiler olarak görüldüğünü kaydetmiştir. ${ }^{20}$ M.S. I. yüzyılın sonlarında yazan Tacitus ise, Cermenlerin öncelikle Merkür'e tapındıklarını ve belli günlerde ona kurbanlar sunduklarını söylemiştir. Sonra Cermen kavimlerinden Süevleri anarak onların özellikle İsis'e kurbanlar sunduklarını ifade etmiştir. Yazar, bu yabancı kültün nereden geldiğini bilmediğini itiraf etmiş ancak sembolünün bir savaş gemisini andırdığından ötürü dışarıdan gelmiş olabileceği düşünmüştür. Ayrıca o, Cermenlerin tanrıları için tapınaklar inşa etmediklerini ve insan biçiminde suretler yontmadıklarını belirtmiştir. Onların gizemli güçlerle ilişkilendirdikleri ağaçlık alanlara kutsallık affetmeleri de yazarın inanç bağlamında zikrettiği diğer bir husustur. ${ }^{21}$ Eseri aynı zamanda notlandıran Birley, Tacitus'un Merkür'e dair sözlerinin kaynağını, Caesar'ın Galyalıların inançlarından bahsederken ki söylediklerinde bulmuştur. Ayrıca o klasik Grek ve Roma kavrayışının, Cermenlerin inançlarını tanımlamadaki etkisine temas etmiştir. Dolayısıyla buradaki Merkür aslında Odin (Wodan, Wotan)'dir ve bugünkü Wodan's day-Wodan'ın günü Wednesday şeklinde; yazarın yine ismini andığı Herkül aslında Thor'a karşılık geldiği ve Thursday olarak; Greklerin Zeus'una ve Romalıların Jupiter'ine benzeyen Mars ise Tiu'dan mülhem Tuesday şeklinde hâlâ canlı bir çağrışıma sahiptir. Birley, Tacitus'un Cermenlerin tapınaklar inşa etmediklerine ve insan suretleri yapmadıklarına dair sözlerinin kaynağının ise Herodot olduğuna kanaat getirmiştir. ${ }^{22}$ Cermenler bunlardan başka daha birçok tanrı ve tanrıçaya sahiptirler. Ancak onların hepsinin kaynağı olarak Odin (Merkür)'i görmüşlerdir. O, savaşçıların önderi ve muhafızıdır. Thor da savaşçı bir tanrıdır. ${ }^{23}$

V. yüzyılda Ammianus biraz belirsiz de olsa, Cermen kavimlerinden biri olan Alamanların bazı şeyleri uğursuz saydıklarından bahsetmiştir. ${ }^{24}$ VIII. yüzyılın Bizanslı Hristiyan tarihçisi Agathias da, onların bazı ağaçlara, nehirlere, tepelere ve vadilere kutsallık affettiklerini, bu yüzden onlara atlar, sığırlar ve daha başka hayvanlardan kurbanlar sunduklarını söylemiştir. ${ }^{25}$ Bundan başka Grek-Roma yazarları bize eski Kelt ve Cermen paganizmi hakkında çok fazla bilgi vermezler. Ancak Cermen paganizmi hakkında en çok detay, İzlandalı Snorri Sturluson'un 1220'de kaleme almış olduğu "Prose Edda" içinde bulunur. Snorri'nin ülkesinin binli yıllardan itibaren Hristiyanlaşmaya başladığı bilinmektedir. ${ }^{26}$ Dolayısıyla bu zamanlar

\footnotetext{
${ }^{20}$ Julius Caesar, Notlar Galya Savaşı Üzerine, çev. Samet Özgüler, Doğu Batı Yayınları, Ankara 2017, s. 193-194.

${ }^{21}$ Tacitus, The Agricola and the Germany, trans. Anthony R. Birley, Oxford University Press, New York 1999, s. 42.

${ }^{22}$ Bkz. Tacitus, The Agricola and the Germany, s. 106-107; Kathryn Starkey, "Imagining an Early Odin: Gold Bracteates as Visual Evidence?", Scandinavian Studies, Vol. 71, No. 4, 1999, s. 380. "Perslerin göreneklerine gelince, işte bildiklerim şunlardır: Tanrı heykeli, tapınak, sunak yapmak gibi şeyler bilmezler; hatta yapanlara deli derler, bu sanırım, onların tanrılara, Yunanlar gibi insan biçimi yakıştırmış olmamalarından ileri gelir.” Bkz. Herodotos, Tarih, çev. Müntekim Ökmen, Türkiye İş Bankası Kültür Yayınları, İstanbul 2018, s. 75.

${ }^{23}$ R. I. Page, İskandinav Mitleri, çev. İsmail Yılmaz, Phoenix Yayınevi, Ankara 2017, s. 10-11. Yer isimleriyle kanıtlanmadığından, Odin'in Cermen mitolojisindeki en yüce tanrı olup olmadığı tartışmalıdır. Starkey, "Imagining an Early Odin: Gold Bracteates as Visual Evidence?", s. 390.

${ }_{24}$ Ammianus Marcellinus, Roma Tarihi, çev. Samet Özgüler, Historia Yayınları, İstanbul 2017, s. 73.

${ }^{25}$ Agathias, The Histories, trans. Joseph D. Frendo, Walter de. Gruyter\&Co., Berlin 1975, s. 15.

${ }^{26}$ March Bloch, Feodal Toplum, çev. Mehmet Ali Kılıçbay, Doğu Batı Yayınları, Ankara 2015, s. 75-86.
} 
Tuesday, Wednesday, Thursday vb. gün isimlerinin ve şiirin putperestliği çağrıştırmasından ötürü yasaklandığ 1 bir dönemdir. ${ }^{27}$

Pagan olan Cermenler vaftiz olduktan sonra eski inançlarına hemen bir mesafe koyamamışlardı. Kilise ise mümkün olduğu ölçüde onlara eski tanrılarını unutturmaya çabalamıștı. Arkeologların çabaları sayesinde gömütlerden çıkarılan çeșitli objeler, silahlar ve giysiler uzunca bir süre Cermenlerde ölümden sonraki hayatın varlığına bir delil olarak yorumlandı. Ancak çağdaş hiçbir kaynakta bu inanışın varlığına dair bir ifade bulunmamaktadır. Büyük cenaze merasimleri ise Frankların merkezi olan Fransa'da kiliselerde ve katedrallerde yaygın bir şekilde yapılmaya başlanmıştı. O zamanın din adamlarının bu törenleri bir pagan geleneği olarak gördüklerine dair de herhangi bir kanıt yoktur. Cermenlerin Hristiyan misyonerlerle karşılaşmadan evvel bu inanç hakkında az çok bilgi sahibi oldukları düşünülmektedir. James'e göre, kilise (Church) sözcüğünün eş anlamlısı olan kyriakón'un onlar tarafından biliniyor olması bunun en bariz göstergesidir. ${ }^{28}$

Hristiyanlık öncesinde paganizm imparatorluğun her tarafında geçerli olduğundan kimse bir başkasını pagan olarak tarif etmiyordu. Kavram IV. yüzyılda ortaya çıktı ve birdenbire gündemini ve gerçekliğini kaybetti. Zira II. Theodosius 423 yılında çıkardığı bir kanunda "Roma İmparatorluğu'nda hiçbir pagan yok" demişti. ${ }^{29}$ Gerçekten de ister zorunlu ister gönüllü olsun, Avrupa kıtasının her tarafına yayılan Cermen kavimleri Hristiyanlığı kabul etmişlerdi. Ancak onların Hristiyanlığı ne doğu kilisesini ne de batı kilisesini tatmin etmişti. Doğu kökenli olan Aryanizm batıya hâkim olan Cermenler içinde kalıcı kökler salmıştı. Libya kökenli olup İskenderiye'de papazlıkla iştigal eden Arius (250-337), IV. yüzyılın ilk çeyreğinin sonları yaklaşırken herkesin tepkisini çeken görüşlerini paylaşmaya başlamış ve Oğul'un tanrısal oluşu hususunu kabul etmediğini açıklamıştı. Onun farklı görüşlerine gerek doğu gerekse batıda toplanan meclislerde resmi olarak tepkiler gösterilmiş, nihayetinde 325 y1lında toplanan I. İznik Konsili ile Arius ve taraftarları aforoz edilmişti. ${ }^{30}$ Ancak Geç Roma İmparatorluğu'nun dini tarihinin karakteristik özelliği olan toleranssızlı ${ }^{31}$, daha başka örneklerde olduğu gibi bu mezhebin de geniş kitlelerce kabulüne giden yolu ardına kadar aralamıştı.

Misyonerler Orta Çağ'daki diğer gruplardan farklı olarak kültürel sınırları belirleme meselesiyle meşguldüler. ${ }^{32}$ Bunun yanında IV. yüzyılın sonlarına doğru artık Roma imparatorları Hristiyanlığı sadece imparatorluk değil dünya dini yapmayı kendilerine vazife bilmişlerdi. ${ }^{33} \mathrm{Bu}$ manada Cermenler arasında Aryanizm'in yayılmasını sağlayan kişi Ulfila (310-383) oldu. Ulfila, ilk Hristiyan Roma imparatoru Konstantin'in ölüm yılında (337) bir Got heyeti içerisinde Konstantinopolis'e gelmiş, 341 y1lında ise Antakya piskoposu Eusebius'un

\footnotetext{
${ }^{27}$ Sigurdur Nordal, "Introduction”, The Prose Edda of Snorri Sturluson Tales from Norse Mythology, trans. Jean I. Young, University of California Press, Berkeley 1965, s. 10.

${ }^{28}$ Edward James, Europe's Barbarians, AD 200-600, Routledge, London 2009, s 216-218.

29 Jan R. Stenger, "The 'Pagans' of Late Antiquity", A Companion to Religion in Late Antiquity, ed. J. Lössl-N. J. Baker-Brian, Blackwell, Hoboken 2018, s. 391.

${ }^{30}$ David Rankin, “Arianism”, The Early Christian World, ed. Philip F. Esler, Routledge, London 2002, s. 975, $997-$ 998.

${ }^{31}$ Mark Humphries, "Christianity and Paganism in the Roman Empire, 250-450 CE", A Companion to Religion in Late Antiquity, ed. J. Lössl-N. J. Baker-Brian, Blackwell, Hoboken 2018, s. 62-63.

${ }^{32}$ Ian Wood, "Missionaries and the Christian Frontier", The Transformation of Frontiers from Late Antiquity to the Carolingians, ed. W. Pohl-I. Wood-H. Reimitz, Brill, Leiden 2001, s. 218.

${ }_{33}$ Ralph W. Mathisen, "Barbarian Bishops and the Churches "in Barbarics Gentibus' During Late Antiquity", Speculum, Vol. 72, No. 3, 1997, s. 665.
} 
görevlendirmesiyle Gotlar arasına bu sefer Hristiyanlığ imparatorluk başkenti için yarattıkları tehdit düşünülürse, uhdesindeki dini vazife bir yana $o$ aynı zamanda imparatorluk ile Gotlar arasında siyasi yönü olan bir arabulucu idi. ${ }^{35}$ Onun Gotlar arasındaki macerası Davud peygamberinkine ziyadesiyle benziyordu. Hz. Davud otuz yaşında davete başlamış, yedi yıl Hebron'da kalmış ve toplam otuz üç yıl İsrailoğulları arasında vaaz etmişti. Ulfila da piskoposluk görevini omuzlarına aldığında otuz yaşındaydı. Yedi yıl Danube'nin kuzeyinde kalmış, ardından Moesia'ya geçmiş ve toplamda kırk yıl Gotlara İncil'i anlatmışt. $^{36}$ V. yüzyılın kilise tarihçileri olan Theodoret ${ }^{37}$, Socrates ${ }^{38}$ ve Sozomen'e ${ }^{39}$ göre o başlangıçta İznik amentüsü üzerine hareket ediyordu ve sonradan Aryanizm'e bağlanmıştı. Her ne olursa olsun gösterdiği başarı onun Aryan bir havari ${ }^{40}$ ya da Gotların havarisi ${ }^{41}$ olarak değerlendirilmesine yol açtı. İncili Got diline çevirdi ${ }^{42}$ ve böylece Got dilinde yazılan ilk metni ortaya çıkardı. ${ }^{43}$ Ulfila içerisinde savaş sahneleri olan Eski Ahit'in Krallar Kitabı'nı Got diline çevirmemişti, zira bu zaten saldırgan olan Gotları daha da şevklendirebilirdi. ${ }^{44}$ Onun bu çabaları sayesinde pagan coğrafya Hristiyan coğrafyasına dönüşmüş oldu. ${ }^{45}$

\section{Cermenik Hristiyanlık}

"Barbar" kavramı yüzyıllarca Avrupa için hayati bir öneme sahip olmuş, Avrupalı'nın kendisini ve medeniyetini tanımlamada anahtar bir rol oynamıştır. Göç Çağı ve sonrasındaki barbarlardan bahsedenler büyük ölçüde Grek ve Romalı yazarlardır. Diğer taraftan VI. yüzyılın ortasında Jordanes'in kaleme aldığ 1 "Gotların Tarihi" adlı eser ise, bir barbarın elinden çıkan ilk yazılı kaynaktır. ${ }^{46}$ Ancak barbar yakıştırması yapılan bu insanlar Jordanes gibi Romalılaşmış, doğal olarak Hristiyanlaşmış ve Latinceyi ustalıkla kullanma becerisine erişmişlerdir. Bunun belki de en somut örneği, bir anlamda Romalılardan daha iyi derecede Latinceye hâkim olan Bede (ö. 735) adlı Anglo-Sakson bir barbarın kaleminden çıkan "İngiliz Halkının Kilise Tarihi” adlı eserdir. Bede’ye göre tarihte İngiliz halkı için asıl dönüm noktası, Roma'nın onlara misyonerler göndermiş olmasıdır. ${ }^{47}$ Bununla beraber diğer barbarların kaleminden çıkan çok fazla bir kayıt bulunmamaktadır. İskandinav halkları X. yüzyıla, Slavlar XI. yüzyıla kadar bu konuda sessiz kalmışlardır. Yine Hunlar gibi mezkûr kıtadaki tarihi

\footnotetext{
${ }^{34}$ Ulfila'nın aslında Kapadokya bölgesi Hristiyanlarından olduğu, sonradan Gotların eline geçtiği ve onlar tarafından Gotlaştırılmış olduğu da düşünülmektedir. Jacques Le Goff, Ortaçağ Batı Uygarlı̆̆ , çev. Hanife Güven-Uğur Güven, Doğu Batı Yayınları, Ankara 2015, s. 33.

35 Orosius, Against the Pagans, trans. A. T. Fear, Liverpool University Press, Liverpool 2010, s. 384; Herwig Wolfram, History of the Goths, trans. Thomas J. Dunlap, University of California Press, California 1990, s. 78; P. J. Geary, Uluslar Miti ve Avrupa Kimliği, çev. Çağdaş Sümer, Yazılama Yayınevi, İstanbul 2017, s. 96-97.

${ }^{36}$ Wolfram, History of the Goths, s. 77.

${ }^{37}$ Theodoret, "The Ecclesiastical History", Nicene and Post-Nicene Fathers of the Christian Church, Vol. III, ed. Philip Schaff-Henry Wace, The Christian Literature Company, New York 1890, s. 131.

${ }^{38}$ Socrates, "The Ecclesiastical History", s. 72.

${ }^{39}$ Sozomen, "The Ecclesiastical History", Nicene and Post-Nicene Fathers of the Christian Church, Vol. II, ed. Philip Schaff-Henry Wace, The Christian Literature Company, New York 1890, s. 373.

${ }^{40}$ Hagith Sivan, "Ulfila's Own Conversion”, The Harvard Theological Review, Vol. 89, No. 4, 1996, s. 373.

${ }^{41}$ Russell, The Germanization of Early Medieval Christianity, s. 135.

${ }^{42}$ Philostorgius, Church History, trans. Philip R. Amidon, Society of Biblical Literature, Atlanta 2007, s. 20; Isidore of Seville, History of the Goths, Vandals, and Suevi, s. 5-6.

${ }^{43}$ James, Europe's Barbarians AD 200-600, s. 2.

${ }^{44}$ James, Europe's Barbarians $A D$ 200-600, s. 38.

${ }^{45}$ Kenneth Scott Latourette, A History of Christianity, Harper\&Row Publishers, New York 1953, s. 100; John M. Howe, "The Conversion of the Physical World", Varieties of Religious Conversion in Middle Ages, ed. James Muldoon, University Press of Florida, 1997, s. 67; Peter Heather-John Matthews, The Goths in the Fourth Century, Liverpool University Press, Liverpool 2004, s. $124 \mathrm{vd}$

${ }^{46}$ James, Europe's Barbarians, AD 200-600, s. 1.

${ }^{47}$ James, Europe's Barbarians AD 200-600, s. 2.
} 
rollerini daha erken icra etmiş olan kavimler de kendilerine ait yazılı bir eser bırakmadan çekilip gitmişlerdir. İşte bu yüzden barbar yakıştırması yapılan halkların tarihi, onların haricindekiler tarafından yazılan bir tarihten ibarettir. Burada önyargılar devreye girdiğinden söz konusu kaynaklar sorgulanmaya oldukça açık hâle gelmektedir. Öte taraftan Jordanes, Tourslu Gregory, Sevilyalı Isidore ve Bede gibi çağın ulusal tarihçileri de modern dünyanın insanının bu kaygısını tabii ki üzerlerinde hissetmemişlerdi. Bede kuzeyin kilise tarihine yoğunlaşmıştı fakat Tourslu Gregory sadece Frankların tarihini yazmamıştı. ${ }^{48}$ Sonuncusu Frank tarihini radikal bir Hristiyan bakış açısıyla kaleme almıştı. ${ }^{49}$ Dolayısıyla Grek ve Romalı yazarlar ve eserleri için gösterilmesi gereken hassasiyet, aynı derecede ulusal tarihçiler için de gözetilmelidir.

Çoğu barbar kavim imparatorluk içine girdiklerinde hâlâ pagan inancında idiler. İspanya'ya girene kadar Vandallar, yine İspanya'ya yerleşene kadar Süevler, İtalya'ya adımlarına atana değin Lombardlar pagan inancındaydılar. Oysa Ostrogotlar ve Vizigotlar imparatorluğa saldırdıklarında büyük oranda Aryanizm mensubu idiler. Yine de Aryanizm bütün Gotlara kendini kabul ettirmeyi başaramamıştı. Meşhur Ostrogot kralı Theodoric'in (ö. 526) annesi Katolik idi ve vaftizi esnasında Got kökenli ismi Erevilia'yı terk ederek Eusebia adını almıştı. ${ }^{50}$ Fakat Aryaznizm'i kabul bir zaman sonra hızla gerçekleşti. V. yüzyılın ortasına tarihlenen bir kroniğin kayıtları bu durumu en açık șekilde göstermektedir. Kroniğe göre, "barbarların yurt tutmadığı hiçbir yerleşim yeri kalmamıştı ve Aryanizm sapkınlığı adeta onların içlerine işlemişti." "51 Burgond kralı Gundobald (ö. 516) Katolik olmuş ancak halkını buna zorlayamamıştı. Burgondların Katolikliği onun ölümünden sonra gerçekleşmişti. ${ }^{52}$ Gotlar ve Gepidlerin Aryanizm tecrübesi ise Hunların 450'lerde çöküşünden sonra başlamıştı. Vizigot kralı Leovigild (ö. 586) koyu bir Aryan olmamasına rağmen, adı geçen mezhebe mensubiyetinin ç1karlarıyla örtüştüğü hususunu açık seçik ifade etmişti. ${ }^{53}$ Tourslu Gregory'e (ö. 594) göre, Vizigot kralı Richared gizlice vaftiz olmuş ve sonra Aryan ve Katolik piskoposlarla görüşmeler yapmıştı. Çok geçmeden Aryan piskoposların mucizeler ve iyileştirme güçlerinden yoksun olduklarından ötürü onlardan uzaklaşmış ve Aryanları III. Toledo Konsili'nden (589) sonra kovuşturmaya başlamışt. ${ }^{54}$ Frankların Hristiyanlaşması ise ancak 500'lerden sonra gerçekleşti. Onların diğer Cermen kavimlerinden farkı, içlerinde kısmen Aryanlar olmasına rağmen, direkt Katolik Hristiyanlığa girmiş olmalarıdır. Clovis şüphesiz bu noktada en çok takdir toplayan Frank kralıdır. Nitekim Vienne piskoposu Avitus, Clovis'e yazdığı bir mektupta "sizin inancınız bizim zaferimizdir" "5 demiştir. Tourslu Gregory Clovis'in direkt olarak paganlıktan Katolik inancına geçtiğini söylese de, piskopos Avitus'un

\footnotetext{
${ }^{48}$ Halsall, Barbarian Migrations and the Roman West 376-568, s. 11.

${ }^{49}$ Helmut Reimitz, "The Providential Past: Visions of Frankish Identity in the Early Medieval History of Gregory of Tours' Historiae (sixth-ninthcentury)", Visions of community in the post-Roman world: the West, Byzantium and the Islamic world, 300-1100, ed. Walter Pohl-Clemens Gantner-Richard Payne, Ashgate Publishing, Farnham 2012, s. 112.

${ }^{50}$ Bkz. The Text and Language of a Vulgar Latin Chronicle (Anonymus Valesianus II), trans. J. N. Adams, University of London, Institute of Classical Studies, London 1976, s. 5, 32.

${ }^{51}$ Bkz. Richard Burgess, "The Gallic Chronicle of 452: A New Critical Edition with a Brief Introduction", Society and Culture in Late Antique Gaul: Revisiting the Sources, ed. Ralph W. Mathisen-Danuta Shanzer, Routledge, New York 2017, s. 67-84; Alexander Murray, From Roman to Merovingian Gaul: A Reader, Broadview Press, Peterborough 2000, s. 76-85.

${ }^{52}$ Gregory of Tours, History of the Franks, trans. E. Brehaut, Columbia University Press, New York 1916, 2.34.

53 John of Biclaro, Chronicle, Conquerors and Chroniclers of Early Medieval Spain, trans. Kenneth Baxter Wolf, Liverpool University Press, Liverpool 2011, 58; Peter Heather, Gotlar, çev. Erkan Avc1, Phoenix Yayınevi, Ankara 2012, s. 393-395.

${ }_{54}^{54}$ Gregory of Tours, History of the Franks, 9. 15.

55 Avitus of Vienne, Letters and Selected Prose, trans. Danuta Shanzer-Ian Wood, Liverpool University Press, Liverpool 2002, s. 369.
} 
mektubuna göre o bir süre Aryanizm ile haşır neşir olmuştu. ${ }^{56}$ Sonraki gelişmelere bakılırsa başlangıçta barbarların kimliklerini muhafaza için adeta bir kalkan görevi icra eden Aryanizm ${ }^{57}$ bu görevi ilelebet muhafaza edememişti.

Eski Ahit'te etnik kimlik anahtar bir rol oynamaktaydı. Zira orada Rab "benim halkım" 58

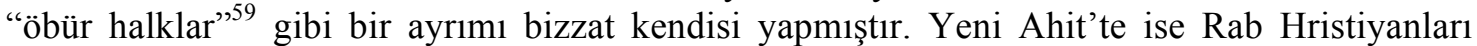
"kendi halkı" konumuna yükseltmiştir. Nitekim bu Pavlus'un bir mektubunda şöyle belirtilmiştir: "Bu yenilikte Grek ve Yahudi, sünnetli ve sünnetsiz, barbar, İskit, köle ve özgür ayrımı yoktur." ${ }^{\prime \prime 0}$ Öyle ki Batı’nın erken teologlarından Tertullian (ö. 220) yelpazeyi oldukça geniş tutmuş, Cermenler, Britonlar, Afrikalılar, Galyalılar ve Romalılar arasında İsa'nın Krallığı'nın sınırları olmadığını ifade etmiştir. ${ }^{61}$ Ancak bu ideal doğu ve batı arasında siyasetin her zaman gölgesinde kalmaya mahkûm olmuştur. Nitekim Vienne piskoposu Avitus, Clovis'i vaftizinden dolayı tebrik ederken, artık kendisinin de Ortodoks bir yönetici olduğunu, Tanrı'ya şükür ki, böyle bir bağışa bundan böyle Bizans'ın tek başına sahip olamayacağını belirtmiştir. ${ }^{62}$ Biyolojik devamlılık, temel kültürel değerlere bağlılık, iletişim dilinde ortaklık ve başkaları tarafından farklı bir grup olarak tanımlanmak etnik kimliği tarifte gözetilen başlıca hususlardır. ${ }^{63}$ Bunun yanında Geç Antik Çağ'daki dini inanışlar etnosu tanımlamada başat rol oynamaktaydı. ${ }^{64} \mathrm{Bu}$ açıdan bakıldığında pagan ulusların din değiştirmeleri Tanrı'nın bir yazgısıdır. Dolayısıyla bir zaman sonra Hristiyanlık etnik kimliği tanımlamada ön plana geçmiştir. İmparatorluğun batı kanadının çöküşü sonrasında batılı tarihçiler önceden imparatorluğa biçtikleri rolü bu sefer barbar krallıklara biçmeye başlamışlardır. ${ }^{65}$ Bu bağlamda Sevilyalı Isidore (ö. 636) seçilmiş halk olarak Vizigotları görmüştür. O kitabında Vizigotlara Kutsal Kitap'tan atalar icat ederek onların geçmişlerinin Romalılardan da eski olduğunu kanıtlamaya çalışmıştır. Fakat bunu yaparken Yahudileri eleştirmekten geri durmamıştır. ${ }^{66}$ Isidore'a göre onlar İsa'nın vekilliğini kabul etmediklerinden İsrail'e layık değillerdir ve bu yüzden Tanrı'nın seçilmiş insanları Hristiyanlardır. Isidore sonraki aşamada ise Vizigotlara Katolik bir geçmiş inşa etmeye çalışmıştır. Bunun için de Romalıları (Bizans) ve onların liderlerini heretik olarak zikretmekten kaçınmamıştır. ${ }^{67}$ Dolayısıyla işin siyaset kısmı daha karmaşıktır. VII. yüzyılda iki kilise arasındaki sürtüşmeler Maximus adlı bir keşiş dolayısıyla epey artmıştır. Maximus, Roma'da tutuklanmış ve Konstantinopolis'e getirilerek heretik

\footnotetext{
${ }^{56}$ Avitus of Vienne, Letters and Selected Prose, s. 137-138.

${ }^{57}$ Geary, Uluslar Miti ve Avrupa Kimliği, s. 138; James, Europe's Barbarians AD 200-600, s. 223-224.

${ }^{58}$ Bkz. Yeremya 32.38.

${ }^{59}$ Bkz. Levililer 20.26.

${ }^{60}$ Bkz. Koleselilere 3.11. Yeni Ahit'te bulunan buna benzer mesajların aksine erken dönem Hristiyanları kendilerini diğerlerinden hep farklı değerlendirmişlerdir. Denise K. Buell, Why this New Race: Ethnic Reasoning in Early Christianity, Columbia University Press, New York 2005, s. 31, 138-139.

${ }^{61}$ Bkz. Geoffrey D. Dunn, Tertullian's Aduersusludaeos, The Catholic University of America Press, Washington 2008, s. 118

${ }^{62}$ Avitus of Vienne, Letters and Selected Prose, s. 370.

${ }^{63}$ Fredrik Barth, "Introduction", Ethnic Groups and Boundaries the Social Organization of Culture Difference, ed. Fredrik Barth, Little, Brown and Company, Boston 1969, s. 10-11.

${ }^{64}$ Halsall, Barbarian Migrations and the Roman West 376-568, s. 37.

${ }^{65}$ Ann Christys, "The Transformation of Hispania after 711", Regna and gentes: the relationship between late antique and early medieval peoples and kingdoms in the transformation of the Roman World, ed. Hans-Werner Goet-J. Jarnut-Walter Pohl, Brill, Leiden 2003, s. 223.

${ }^{66}$ Romalılar ve Gotlar birbirlerine yakınlaştıkça Yahudilerin ötekiliği daha fazla gündeme gelmiştir. Geary, Uluslar Miti ve Avrupa Kimliği, s. 142. Avrupa'daki antisemitizmin doğuşunun bu gerilimden kaynaklandığ düşünülmektedir. Jacques Le Goff, Avrupa'nın Doğuşu, çev. Timuçin Binder, Literatür Yayınları, İstanbul 2008, s. 25.

${ }^{67}$ Jamie Wood, "Religiones and gentes in Isidore of Seville's Chronica maiora", Post-Roman Transitions Christian and Barbarian Identities in the Early Medieval West, ed. Walter Pohl-Gerda Heydemann, Brepols, Turnhout 2013, s. 126, 132, 135, 146, 148.
}

\section{History Studies}


olduğu gerekçesiyle yargılanmıştır. Kendisine yöneltilen "Romalıları niçin seviyorsun ve Greklerden nefret ediyorsun?" sorusu karşısında keşiş şu yanıtı vermiştir: "Bize verilen emir uyarınca kimseden nefret etmeyiz. Aynı inancı taşıdığım için Romalıları seviyorum ve aynı dili paylaştı̆̆ım için de Grekleri seviyorum."

X. yüzyılda Kutsal Roma Cermen İmparatoru I. Otto, Cremonalı Liudprand'un içinde bulunduğu bir elçilik heyetini Konstantinopolis'e göndermiş, batının emperyal iddiasını sezinleyen Bizans imparatoru Nicephorus heyete "siz Romalı değilsiniz, Lombardsınız" şeklinde bir söz söylemiş, buna karşın Liudprand şu şekilde mukabelede bulunmuştur: "Biz, Lombardlar, Saksonlar, Lothringenler, Bavyeralılar, Suabiyalılar ve Burgondlar, aramızdan birine düşmanlık beslediğimizde "siz Romalısınız"dan daha tahkir edici bir söz bulamayız. Bizim için Romalı küstah, korkak, haris, lüks düşkünü, yalancı ve ahlaksız demektir." ${ }^{69} \mathrm{Bu}$ mesele aslında yüzyıllar içinde Romalı kimliğinin geçirdiği evrim ile yakından ilişkilidir. Başlangıçta Romalılar kıtanın yeni kavimlerine barbar yakıştırmasını yaparken, sonraları barbar, Romalı olmuştur. Fakat bu yorum aşırı değerlendirmelere yol açmamalıdır. Roma kültürü her daim etkisini korumuş, barbar yöneticiler kendi statülerini ortaya koyarken ona yönelme gereği duymuşlardır. Sonuçta Dawson'un ${ }^{70}$ deyişiyle, Avrupa barbar istilaları karşısında ortadan kalkma tehlikesini yaşamayan Katolik Kilisesi sayesinde dini birliğini tekrardan kurmuştur. İște bu yüzden muhtemelen Grek Doğu'dan mülhem olan Latin Batı ifadesi, Roma İmparatorluğu'nun Akdeniz'e dayalı olarak oluşturduğu ve kendi ağırlığını henüz hissettirdiği zamanların siyasi, sosyal ve dini olaylarını tarif ederken kullanılmasına rağmen, Cermenlerin Katolikleşmesinden sonraki süreçte de canlılığını yine devam ettirerek Batı Avrupa'nın siyasi ve kültürel gelişmelerini anlamlandırmada en çok tercih edilen kavram olmuştur. $^{71}$

\section{Sonuç}

Avrupa görünürde binli yıllarda başlayan istikrarına uzun soluklu göç, istila ve fetih devirlerinden sonra kavuşabilmişti. Zira imparatorluğun batı kısmını nihayete erdiren ve bu topraklarda kendi krallıklarını tesis eden halklar kısa süre sonra birbirleriyle mücadeleye girişmişlerdi. Epey uzun müddet devam edecek olan imparatorluğun doğu kısmı ise eski topraklardaki hakimiyetini yeniden canlandırmak için daima uygun bir firsat kollamıştı. Sonunda söz konusu krallıklar iç krizler dolayısıyla zayıfladı, onlara yıkıcı darbeyi ise ya passioner ruhu (iç enerji) yeni yakalamış olan akrabaları ya da Doğu Roma vurmuştu. İtalya'daki Ostrogotları ve Kuzey Afrika'daki Vandalları Doğu Roma ortadan kaldırdı. Fransa'nın bir kısmına ve Almanya'ya hâkim olan Franklar iç krizlerle boğuşurken kuzeyin saldırgan insanlarına karşı koyamamışlardı. İspanya'daki Vizigotların sonunu getirenler ise Müslümanlar olmuştu. Danimarkalılar da Anglo-Sakson krallıklarını hakimiyet altına almışlardı. Bütün bunlar meselenin siyasi boyutuydu. Roma İmparatorluğu'nun batı kanadı siyasi olarak ortadan kalkmasına rağmen, yüzyılların birikimi olan Latin kültürü Cermen kavimlerini bu pota içinde eritmeyi becerebilmişti.

\footnotetext{
${ }^{68}$ Augustine Casiday, "Christianity", A Companion to Religion in Late Antiquity, ed. J. Lössl-N. J. Baker-Brian, Blackwell, Hoboken 2018, s. 284. Heretiklik ve ulusalcılık arasında bir sorgulama için bkz. John Alexander Armstrong, Milliyetçilikten Önce Mitler, çev. S. Erdem Türközü, İletişim Yayınları, İstanbul 2018, s. 253 vd.

${ }^{69}$ Liudprand of Cremona, The Embassy to the Constantinople, The Works of Liudprand of Cremona, trans. F. A. Wright, Routledge, London 1930, s. 242-243.

${ }^{70}$ Christopher Dawson, Batının Oluşumu, çev. Dinç Tayanç, Dergâh Yayınları, İstanbul 1997, s. 60.

${ }^{71}$ Tom O'Loughlin, "The Latin West in the Period of Transition from 'the Late Roman Empire' to 'Early Medieval Europe': Consolidation and Innovation”, A Companion to Religion in Late Antiquity, ed. J. Lössl-N. J. Baker-Brian, Blackwell, Hoboken 2018, s. 81.
} 
Onların başlangıçta kimliklerini korumaya hizmet eden Aryanizm'i kolayca benimsemeleri, ileride yaşanabilecek olan bu dönüşümün belki de ilk sinyallerini vermişti. Her bir Cermen kavminin farklı bir Aryanizm tecrübesi olmuştu. Bu durumun ortaya çıkmasında büyük ölçüde krallar belirleyici durumdaydı. Vizigot kralı Leovigild gibi Aryanizm'i siyasi bir koz olarak kullanan krallar, hâkimiyetleri altındaki putperestlere ve Katoliklere korkulu anlar yaşatmışlardı. Fakat bu süreç çoğu zaman bir sonraki kral zamanında tersine dönmekteydi. Kıtanın Latin kültürü bütün Cermen kavimlerini zamanla etkisi altına alsa da, sonuçta Avrupa Hristiyanlığına Roma İmparatorluğu'nun ortadan kalkmasından sonra Cermen damgası vurulmuştu.

\section{Kaynaklar}

ABU-LUGHOD, Janet L., Before European Hegemony The World System A.D. 1250-1350, Oxford University Press, New York 1989.

AGATHIAS, The Histories, trans. Joseph D. Frendo, Walter de. Gruyter\&Co., Berlin 1975.

AMMIANUS MARCELLINUS, Roma Tarihi, çev. Samet Özgüler, Historia Yayınları, İstanbul 2017.

ARMSTRONG, John Alexander, Milliyetçilikten Önce Mitler, çev. S. Erdem Türközü, İletişim Yayınlar1, İstanbul 2018.

AVITUS OF VIENNE, Letters and Selected Prose, trans. Danuta Shanzer-Ian Wood, Liverpool University Press, Liverpool 2002.

BAKER, Simon, Eski Roma Bir Imparatorluğun Yükselişi ve Çöküşü, çev. Ekin Duru, Say Yayınları, İstanbul 2017.

BARTH, Fredrik, "Introduction", Ethnic Groups and Boundaries the Social Organization of Culture Difference, ed. Fredrik Barth, Little, Brown and Company, Boston 1969, s. 938.

BLOCH, March, Feodal Toplum, çev. Mehmet Ali Kılıçbay, Doğu Batı Yayınları, Ankara 2015.

BUELL, Denise K., Why this New Race: Ethnic Reasoning in Early Christianity, Columbia University Press, New York 2005.

BURGESS, Richard, "The Gallic Chronicle of 452: A New Critical Edition with a Brief Introduction", Society and Culture in Late Antique Gaul: Revisiting the Sources, ed. Ralph W. Mathisen-Danuta Shanzer, Routledge, New York 2017, s. 52-84.

CARTLEDGE, Paul, The Greeks A Portrait of Self and Others, Oxford University Press, New York 2002.

CASIDAY, Augustine, "Christianity", A Companion to Religion in Late Antiquity, ed. J. LösslN. J. Baker-Brian, Blackwell, Hoboken 2018, s. 277-296.

CHRISTYS, Ann, "The Transformation of Hispania after 711", Regna and gentes: the relationship between late antique and early medieval peoples and kingdoms in the transformation of the Roman World, ed. Hans-Werner Goet-J. Jarnut-Walter Pohl, Brill, Leiden 2003, s. 219-242.

CLAUDIAN, Against Rufinus, trans. Maurice Platnauer, Harward University Press, London 1990. 
DAWSON, Christopher, Batının Oluşumu, çev. Dinç Tayanç, Dergâh Yayınları, İstanbul 1997.

DUNN, Geoffrey D., Tertullian's AduersusIudaeos, The Catholic University of America Press, Washington 2008.

EUSEBIUS, "Oration in Praise of Constantine", Nicene and Post Nicene Fathers, Vol. I, ed. P. Shaff-H. Wace, Charles Scribner's Sons, New York 1904, s. 581-610.

GEARY, P. J., Uluslar Miti ve Avrupa Kimliği, çev. Çağdaş Sümer, Yazılama Yayınevi, İstanbul 2017.

GEARY, Patrick J., Before France and Germany: The Creation and Transformation of the Merovingian World, Oxford University Press, New York 1988.

GILLETT, Andrew, "The Mirror of Jordanes: Concepts of the Barbarian, Then and Now", $A$ Companion to Late Antiquity, ed. Philip Rousseau, Blackwell, London 2009, s. 392408.

GOFFART, Walter, "The Theme of 'The Barbarian Invasions' in Late Antique and Modern Historiography", Das Reich und die Barbaren, Evangelos K. Chrysos-Andreas Schwarcz, Böhlau Verlag, Köln 1989, s. 87-107.

GREGORY OF TOURS, History of the Franks, trans. E. Brehaut, Columbia University Press, New York 1916.

HISTORY

HALSALL, Guy, Barbarian Migrations and the Roman West 376-568, Cambridge University Press, Cambridge 2007.

HAVERFIELD, F., The Romanization of Roman Britain, At the Clarendon Press, Oxford 1912.

HEATHER, Peter -MATTHEWS, John, The Goths in the Fourth Century, Liverpool University Press, Liverpool 2004.

HEATHER, Peter, "Goths and Huns, c. 320-425", The Cambridge Ancient History, Vol. XIII, ed. Averil Cameron-Peter Garnsey, Cambridge University Press, Cambridge 2007, s. 487-515.

HEATHER, Peter, Gotlar, çev. Erkan Avcı, Phoenix Yayınevi, Ankara 2012.

HERODOTOS, Tarih, çev. Müntekim Ökmen, Türkiye İş Bankası Kültür Yayınları, İstanbul 2018.

HOWE, John M., "The Conversion of the Physical World", Varieties of Religious Conversion in Middle Ages, ed. James Muldoon, University Press of Florida, Gainesville 1997, s. 63-78.

HUMPHRIES, Mark, "Christianity and Paganism in the Roman Empire, 250-450 CE", $A$ Companion to Religion in Late Antiquity, ed. J. Lössl-N. J. Baker-Brian, Blackwell, Hoboken 2018, s. 61-80.

ISIDORE OF SEVILLE, History of the Goths, Vandals, and Suevi, trans. G. Donini-G. B. Ford, Brill, Leiden 1970.

JAMES, Edward, Europe's Barbarians, AD 200-600, Routledge, London 2009.

JAMES, Edward, The Origin of France from Clovis to Capetians 500-1000, The Macmillan Press, London 1982.

\section{History Studies}


JOHN OF BICLARO, Chronicle, Conquerors and Chroniclers of Early Medieval Spain, trans. Kenneth Baxter Wolf, Liverpool University Press, Liverpool 2011.

JONES, Peter, Geldim Gördüm Yendim, çev. Funda Sezer, Say Yayınları, İstanbul 2019.

JORDANES, The Origin and Deeds of the Goths, trans. Charles C. Mierow, Princeton University Press, Princeton 1908.

JULIUS CAESAR, Notlar Galya Savaşı Üzerine, çev. Samet Özgüler, Doğu Batı Yayınları, Ankara 2017.

LATOURETTE, Kenneth Scott, A History of Christianity, Harper\&Row Publishers, New York 1953.

LE GOFF, Jacques, Avrupa'nın Doğuşu, çev. Timuçin Binder, Literatür Yayınları, İstanbul 2008.

LE GOFF, Jacques, Ortaçă̆ Batı Uygarlı̆̆l, çev. Hanife Güven-Uğur Güven, Doğu Batı Yayınlar1, Ankara 2015.

LIUDPRAND OF CREMONA, The Embassy to the Constantinople, The Works of Liudprand of Cremona, trans. F. A. Wright, Routledge, London 1930.

MATHISEN, Ralph W., "Barbarian Bishops and the Churches 'in Barbarics Gentibus' During Late Antiquity", Speculum, Vol. 72, No. 3, 1997, s. 664-697.

MONTESQUIEU, Kanunların Ruhu Üzerine, çev. Berna Günen, Türkiye İş Bankası Kültür Yayınlar1, İstanbul 2019.

MURRAY, Alexander, From Roman to Merovingian Gaul: A Reader, Broadview Press, Peterborough 2000.

O'LOUGHLIN, Tom, "The Latin West in the Period of Transition from 'the Late Roman Empire' to 'Early Medieval Europe': Consolidation and Innovation", A Companion to Religion in Late Antiquity, ed. J. Lössl-N. J. Baker-Brian, Blackwell, Hoboken 2018, s. 81-97.

OROSIUS, Against the Pagans, trans. A. T. Fear, Liverpool University Press, Liverpool 2010.

NORDAL, Sigurdur, "Introduction", The Prose Edda of Snorri Sturluson Tales from Norse Mythology, trans. Jean I. Young, University of California Press, Berkeley 1965, s. 7-15.

PAGE, R. I., İskandinav Mitleri, çev. İsmail Yılmaz, Phoenix Yayınevi, Ankara 2017.

PHILOSTORGIUS, Church History, trans. Philip R. Amidon, Society of Biblical Literature, Atlanta 2007.

POHL, Walter, "Christian and Barbarian Identities in the Early Medieval West: Introduction", Post-Roman Transitions Christian and Barbarian Identities in the Early Medieval West, ed. Walter Pohl-Gerda Heydemann, Brepols, Turnhout 2013, s. 1-46.

RANKIN, David, “Arianism”, The Early Christian World, ed. Philip F. Esler, Routledge, London 2002, s. 975-1001.

REIMITZ, Helmut, "The Providential Past: Visions of Frankish Identity in the Early Medieval History of Gregory of Tours' Historiae (sixth-ninthcentury)", Visions of community in the post-Roman world: the West, Byzantium and the Islamic world, 300-1100, ed. 
Walter Pohl-Clemens Gantner-Richard Payne, Ashgate Publishing, Farnham 2012, s. 109-135.

SIVAN, Hagith, "Ulfila's Own Conversion", The Harvard Theological Review, Vol. 89, No. 4, 1996, s. 373-386.

SOCRATES, Ecclesiastical History, Nicene and Post-Nicene Fathers of the Christian Church, Vol. II, ed. Philip Schaff-Henry Wace, The Christian Literature Company, New York 1890, s. 1-178.

SOZOMEN, The Ecclesiastical History, Nicene and Post-Nicene Fathers of the Christian Church, Vol. II, ed. Philip Schaff-Henry Wace, The Christian Literature Company, New York 1890, s. 239-427.

STARKEY, Kathryn, "Imagining an Early Odin: Gold Bracteates as Visual Evidence?", Scandinavian Studies, Vol. 71, No. 4, 1999, s. 373-392.

STENGER, Jan R., “The 'Pagans' of Late Antiquity", A Companion to Religion in Late Antiquity, ed. J. Lössl-N. J. Baker-Brian, Blackwell, Hoboken 2018, s. 391-409.

TACITUS, The Agricola and the Germany, trans. Anthony R. Birley, Oxford University Press, New York 1999.

THE TEXT AND LANGUAGE OF A VULGAR LATIN CHRONICLE (ANONYMUS VALESIANUS II), trans. J. N. Adams, University of London, Institute of Classical Studies, London 1976.

THEODORET, The Ecclesiastical History, Nicene and Post-Nicene Fathers of the Christian Church, Vol. III, ed. Philip Schaff-Henry Wace, The Christian Literature Company, New York 1890, s. 33-159.

TIRR, D. A., "The Attitude of the West towards the Avars", Acta Archaeologica, 28, 1.2, 1976, s. 111-121.

VASILIEV, Alexander A., Bizans Imparatorluğu Tarihi, çev. Tevabil Alkaç, Alfa Yayınları, İstanbul 2016.

WALLACE-HADRILL, J. M., The Barbarian West A.D. 400-1000, Harper Torchbooks, New York 1962.

WOLFRAM, Herwig, History of the Goths, trans. Thomas J. Dunlap, University of California Press, California 1990.

WOOD, Ian, "Missionaries and the Christian Frontier", The Transformation of Frontiers from Late Antiquity to the Carolingians, ed. W. Pohl-I. Wood-H. Reimitz, Brill, Leiden 2001, s. 209-218.

WOOD, Jamie, "Religiones and gentes in Isidore of Seville's Chronica maiora", Post-Roman Transitions Christian and Barbarian Identities in the Early Medieval West, ed. Walter Pohl-Gerda Heydemann, Brepols, Turnhout 2013, s. 125-168.

ZOSIMUS, New History, trans. Ronald T. Ridley, Australian Association for Byzantine Studies, Melbourne 1982. 